\title{
Equity Within Ecological Limits: Grand Challenge for Sustainable Consumption
}

\author{
Sylvia Lorek* \\ Sustainable Europe Research Institute, Köln, Germany
}

Keywords: sustainable consumption, governance, SDGs, lifestyles, equity, justice, research challenge

\section{INTRODUCTION}

Three decades have passed since the UN Conference for Environment and Development identified unsustainable patterns of consumption as a major cause of environmental deterioration as well as an issue aggravating poverty and imbalance. Consequently, in the conference outcome, Agenda 21 , the so-called developed countries were addressed to take the lead in achieving sustainable consumption patterns and developing countries were asked to avoid unsustainable patterns in their development process (United Nations, 1992). According to Agenda 21, consumption patterns include consumption by industries, governments, households, and individuals. In the years and decades following Agenda 21, mainly the consumption of individuals and households got specific attention and were addressed in policy and research under the term "sustainable consumption." This created a shift from previously recognizing humans mainly as victims of environmental degradation and pollution resulting from industry and their production processes to sources of such problems through the increasing demand of resource intensive products and services. Since then, science, policy, and practice searched for paths toward more sustainable, and respectively less wasteful, modes of consumption. To a broad extent, emphasis was-and still is-given to encourage consumers to buy more sustainable products and/or services and to shift behavior toward more sustainable and less wasteful modes of consumption. Research, however, has shown, that appealing predominantly to consumers does not lead to the required change (Mont et al., 2013), it just makes consumers the scapegoats for further unsustainable consumption and production patterns (Akenji, 2014).

The UN 2030 Agenda for Sustainable Development with its 17 Sustainable Development Goals (SDGs) again highlighted the need for sustainable consumption through the formulation of SDG 12 "Ensure sustainable consumption and production patterns" (UN, 2015). It goes a bit further than Agenda 21, as it lines out the need for substantial changes in patterns of consumption and production-at least in its headline and parts of the seven targets. Other targets, and especially the indicators of SDG 12, however, only provide a partial conceptualization of sustainable consumption focused predominantly on efficiency and waste reduction. This reveals a substantial gap between current scientific understanding of sustainable consumption and production (SCP) and how this field is articulated in political and societal debates (Bengtsson et al., 2018).

\section{THE ECOLOGICAL CHALLENGE}

To achieve global sustainability by keeping global warming below 2 , although ideally below $1.5^{\circ} \mathrm{C}$, and stopping biodiversity loss, the overall resource consumption has to be reduced drastically. As the UNEP Emissions Gap Report 2020 points out, countries must collectively increase their ambitions threefold to keep the chance to achieve the $2^{\circ} \mathrm{C}$ goal and more than fivefold for the $1.5^{\circ} \mathrm{C}$ 
goal. Based on the current commitments made by the countries, however, projections calculate a possibility of warming of $3.2^{\circ} \mathrm{C}$ by the end of the century (UNEP, 2020). The report of UNEPs International Resource Panel contributes and specifies further where the challenges are: reducing material use is also a key aspect for reaching the climate goals. Emissions from the production of materials increased from 5 gigatons $(\mathrm{Gt})$ of $\mathrm{CO}_{2}$-equivalent in 1995 to $11 \mathrm{Gt}$ in 2015 , with their share of global emissions rising from 15 to $23 \%$ (Hertwich et al., 2020).

What might look like a production side problem to be solved by efficiency and technological development reveals its challenge for sustainable lifestyles when taking a consumption perspective. Mainly residential buildings and light-duty vehicles come into focus then, accompanied by the global increase in meat and dairy consumption as well as flights. These are the major areas where changes in in lifestyles have to emerge. Science has been highlighting these big points for more than 20 years, and they have been emphasized by more recent studies (Lorek and Spangenberg, 2001; Akenji et al., 2019).

What stands out regarding the demand for energy, material, and land use, and thus are the factors contributing most to GHG emissions and biodiversity loss, are:

- Food, with emphasis on the consumption of animal products, thus meat and dairy

- Housing, with its increasing per capita living area which needs to be built, heated, and equipped

- Mobility, with the problematic aspects of individual motorized transport and flights.

Changing habits here, however, is far from being an individual decision. All these areas are characterized by large, often global, systems of provisioning. The challenge for sustainable consumption is to accept that systemic challenge (Lorek and Vergragt, 2015).

A crucial aspect not to be underestimated is that all the facets of unsustainable lifestyles are actually oriented to the idea of attaining more, which is promised by the political commitments to (ever) rising GDP. SDG 8 "Promote sustained, inclusive, and sustainable economic growth, full and productive employment, and decent work for all" (UN, 2015) is a shining manifestation of the growth paradigm. But keeping the $1.5^{\circ}$ goal in mind there is no proof that it can be achieved through growth policies, not even green growth (Buckle et al., 2020; European Environment Agency, 2020). So, in times of uncertainty, the precautionary principle deserves more attention. This urgency becomes even clearer when considering the fact that an extensive number of material resources and related Greenhouse Gas Emissions will be needed to set up a more sustainable infrastructure and that broad parts of the world still need to increase their consumption to escape a stage of poverty. This means the reduction requirements for the global consumer class are even larger (Alfredsson et al., 2018).

The structures shaping consumption patterns toward a more sustainable stage are influenced by the built environment, by financial and policy frameworks, and by a variety of social and cultural conventions. Individuals as consumers can be active participants in changing their lifestyles through taking individual steps to reduce personal consumption. As citizens, they can foster societal change through civic engagement, initiating adequate adjustments in the social, cultural, political, and economic systems. Nevertheless, municipality decision makers as well as governments at the regional, national, and supra-national level are in the position to establish the supporting conditions under which lifestyle changes can occur. Their challenge is to adapt regulations and make infrastructure investments supporting citizens to overcome actual lock-in situations through, for example, shaping cycling as a default option in an urban context complementing or, better, replacing omnipresent car mobility.

\section{THE EQUITY CHALLENGES}

Achieving sustainable consumption is far from being an ecological problem only. The chance for sustainable consumption to meet the global challenges also depends on the ability to raise the consumption of broad parts of the world population from scarcity to a sustainable level and to reduce inequality among and within countries. More equal societies perform better on a wide range of social indicators of well-being, including social trust and support for democratic institutions, political participation, educational outcomes, health status, crime, and opportunities for social mobility (Wilkinson and Pickett, 2010). An equity approach to sustainable consumption can turn traditional approaches like "prices have to reflect the ecological truth" upside down by shifting attention from claims from low-income groups that they cannot afford sustainability (sustainable products) to the factual behavior of the polluter elite. Compliance with the $1.5^{\circ} \mathrm{C}$ goal of the Paris Agreement will require reducing consumption emissions to a per capita lifestyle footprint of around $2-2.5 \mathrm{tCO}_{2} \mathrm{e}$ by 2030 . If this value is to be applied to the entire global population equally, this would require that the wealthiest $1 \%$ of the global population reduce their current emissions by at least a factor of 30, while per capita emissions of the poorest $50 \%$ could increase by around three times their current levels on average (UNEP, 2020). The latest research demonstrates that the actual inequality of global income mainly supports transport and luxury for polluter elites. A more equal distribution of income, instead, would shape household energy footprints toward a more subsistence level consumption. Therefore, more equitable lifestyles might be more compatible with climate constraints (Oswald et al., 2021). For this reason, sustainable consumption research partly overlaps with the research on degrowth (Latouche, 2007; Hobson, 2013; Lorek and Fuchs, 2013; Spangenberg, 2014), which intends to develop economic perspectives based on the wellbeing of all independent from economic growth (D'Alisa et al., 2014). Research on and implementation of other measures of progress than GDP, which focus on human wellbeing and the "good life", are an emerging approach as well (Hoekstra, 2019). As novel methods of data decomposition show, the assumed strong correlation between growth, emissions, and human development is not necessarily given. Thus, increasing human well-being can be approached in a way decoupled from growth (Steinberger et al., 2020). 
Finally, interventions for sustainable consumption need to explicitly address racial, class, and gender dimensions, not least to avoid public protest. This requires important social innovations, for example in governance processes. Citizens' assemblies, for example, may foster dialogue and engagement about the complex trade-offs on the way to achieve sustainable lifestyles and could enable a broad social ownership for the transition processes (Newell et al., 2021).

\section{THE WAY AHEAD FOR THE RESEARCH FIELD}

The research on sustainable consumption evolved in parallel with the developments in the policy field. Analyzing the evolution of sustainable consumption research, Liu et al. (2017) identified that, since the late 1990s, the environmentally friendly and unfriendly behaviors of citizen-consumers had been a common concern. In order to support sustainable consumption patterns, research already turned toward policies. In the early 2000s, the research topic began to take off (Liu et al., 2017), for example, due to larger projects in the European national and EU context, expanding to different research topics as well as research methods ranging from the environmental policy perspective (Mathai et al., 2020) to interdisciplinary and multi-industry collaborations. Life Cycle Assessments (LCAs) were carried out to measure the environmental impacts of product systems or services and studies investigated the key influencing factors of sustainable consumption from a psychological via social and economic to political perspective, showing the complexity of directions where the shifts in recent consumption patterns have to come from (Hertwich, 2005; Cohen et al., 2013; Salazar et al., 2013; Steg, 2015; Suski et al., 2021). An important strain of research contributed to the development of practice theory (Welch and Warde, 2015). Various handbooks appeared regarding consumption governance (Mont, 2019) or paving the ground for directing further research (Reisch and Thogersen, 2015). Throughout all these efforts, sustainable consumption research has gradually developed into a more systematic but also diverse field. Particular attention was given to theory building e.g., through distinguishing between weak sustainable consumption (governance) focusing on demand for more sustainable products and services and strong sustainable consumption (Fuchs and Lorek, 2005), highlighting the need for absolute reduction in material consumption and environmental impact (Lorek and Spangenberg, 2014; Akenji et al., 2016). As the "what needs to be done" is rather settled (the systems of food, housing, and mobility) the "how" now needs much more attention to bridge the knowledge-to-action gap in consumer behavior as well as in policy making.

Therefore, the current systemic challenge has been receiving more attention, and the question of how political and societal frameworks may adequately steer toward sustainable consumption (and related production) systems is being considered. Consumption is just one aspect of a larger intertwined system of investments, production, trade, consumption, and waste and has material, economic, cultural, institutional, and power aspects. Changing consumption thus entails changing the entire system (Lorek and Vergragt, 2015). Thus, in a sustainable consumption context, infrastructures, institutions, social organization, and social norms also need to be investigated (Toulouse et al., 2019), as well as the ways in which modes of "living with enough" could solidify between floor and ceiling of sustainable consumption corridors through democratic and participatory processes (Fuchs et al., 2021, Sahakian et al., 2021). This includes a closer investigation of power relations (Fuchs et al., 2016). To bring the research field forward, trans-disciplinarity needs to be encouraged, involving also civil society agents next to researchers working in the fields of climate change mitigation, sustainable consumption, human development, ecological economics, energy modeling, industrial ecology, social change, behavior change, social and global justice, marketing, and much more.

In this Specialty Section on Sustainable Consumption, specific attention will be given to the following themes:

- Analysis of contraction and convergence pathways for sustainable consumption

- Analysis of power dynamics fostering inequality along the production chains and undermining sustainable consumption opportunities and how to overcome them

- Approaches of collective consumption, production, and ownership

- Contributions of public procurement to foster development of sustainable consumption and production systems

- Defining quantitative and qualitative indicators for societal wellbeing

- Development and analysis of policies fostering strong sustainable consumption

- Dynamics of everyday life consumption and opportunities for social change to more sustainable patterns

- Identification of winners and losers of sustainable consumption (and production) systems

- Macro-economic modeling considering upper and lower limits of consumption in pursuit of sustainable societies

- Measurement of sustainability for production and consumption

- Regional strategies shortening distances and fostering resilience in food and energy provision.

\section{AUTHOR CONTRIBUTIONS}

The author confirms being the sole contributor of this work and has approved it for publication. 


\section{REFERENCES}

Akenji, L. (2014). Consumer scapegoatism and limits to green consumerism. J. Clean. Prod. 63, 13-23. doi: 10.1016/j.jclepro.2013.05.022

Akenji, L., Bengtsson, M., Bleischwitz, R., Tukker, A., and Schandl, H. (2016). Ossified materialism: introduction to the special volume on absolute reductions in materials throughput and emissions. J. Clean. Prod. 132, 1-12. doi: 10.1016/j.jclepro.2016.03.071

Akenji, L., Lettenmeier, M., Toivio, V., Koide, R., and Amellina, A. (2019). 1.5 Degree Lifestyles. Hayama: Institute for Global Environmental Strategies, Aalto University, and D-mat ltd.

Alfredsson, E., Bengtsson, M., Brown, H. S., Isenhour, C., Lorek, S., Stevis, D., et al. (2018). Why achieving the Paris Agreement requires reduced overall consumption and production. Sustain. Sci. Pract. Policy 14, 1-5. doi: 10.1080/15487733.2018.1458815

Bengtsson, M., Alfredsson, E., Cohen, M., Lorek, S., and Schroeder, P. (2018). Transforming systems of consumption and production for achieving the sustainable development goals: moving beyond efficiency. Sustain. Sci. 13, 1533-1547. doi: 10.1007/s11625-018-0582-1

Buckle, S., Ellis, J., Jaber, A. A., Rocha, M., Anderson, B., and Bjersér, P. (2020). Addressing the COVID-19 and Climate Crises: Potential Economic Recovery Pathways and Their Implications For Climate Change Mitigation, NDCs and Broader Socio-Economic Goals. Paris: OECD.

Cohen, M. J., Brown, H. S., and Vergragt, P. (2013). Innovations in Sustainable Consumption: New Economics, Socio-Technical Transitions and Social Practices. Cheltenham: Edward Elgar Publishing.

D'Alisa, G., Demaria, F., and Kallis, G. (2014). Degrowth: A Vocabulary for a New Era. Milton Park: Routledge. doi: 10.4324/9780203796146

European Environment Agency (2020). Growth Without Economic Growth. Copenhagen: EEA.

Fuchs, D., Di Giulio, A., Glaab, K., Lorek, S., Maniates, M., Princen, T., et al. (2016). Power: the missing element in sustainable consumption and absolute reductions research and action. J. Clean. Prod. 132, 298-307. doi: 10.1016/j.jclepro.2015.02.006

Fuchs, D., Sahakian, M., Gumbert, T., Di Giulio, A., Maniates, M., Lorek, S., et al. (2021). Consumption Corridors: Living a Good Life Within Sustainable Limits. London: Routledge. doi: 10.4324/9780367748746

Fuchs, D. A., and Lorek, S. (2005). Sustainable consumption governance: a history of promises and failures. J. Consum. Policy 28, 261-288. doi: 10.1007/s10603-005-8490-z

Hertwich, E., Lifset, R., Pauliuk, S., Heeren, N., Ali, S., Tu, Q., et al. (2020). Resource Efficiency and Climate Change: Material Efficiency Strategies for a Low-Carbon Future. Nairobi: International Resource Panel, UNEP.

Hertwich, E. G. (2005). Life cycle approaches to sustainable consumption: a critical review. Environ. Sci. Technol. 39, 4673-4684. doi: 10.1021/es0497375

Hobson, K. (2013). 'Weak'or 'strong'sustainable consumption? Efficiency, degrowth, and the 10 year framework of programmes. Environ. Plan. C Govern. Policy 31, 1082-1098. doi: 10.1068/c12279

Hoekstra, R. (2019). Replacing GDP by 2030: Towards a Common Language for the Well-Being and Sustainability Community. Cambridge: Cambridge University Press. doi: 10.1017/9781108608558

Latouche, S. (2007). "Sustainable consumption in a 'de-growth' perspective," in Sustainable Consumption, Ecology and Fair Trade (S. 192-199). London: Routledge.

Liu, Y., Qu, Y., Lei, Z., and Jia, H. (2017). Understanding the evolution of sustainable consumption research. Sustain. Dev. 25, 414-430. doi: $10.1002 /$ sd.1671

Lorek, S., and Fuchs, D. (2013). Strong sustainable consumption governance-precondition for a degrowth path? J. Clean. Prod. 38, 36-43. doi: $10.1016 /$ j.jclepro.2011.08.008

Lorek, S., and Spangenberg, J. H. (2001). Indicators for environmentally sustainable household consumption. Int. J. Sustain. Dev. 4, 101-120. doi: 10.1504/IJSD.2001.001549

Lorek, S., and Spangenberg, J. H. (2014). Sustainable consumption within a sustainable economy-beyond green growth and green economies. J. Clean. Prod. 63, 33-44. doi: 10.1016/j.jclepro.2013.08.045

Lorek, S., and Vergragt, P. J. (2015). "Sustainable consumption as a systemic challenge: inter-and transdisciplinary research and research questions," in
Handbook of Research on Sustainable Consumption. Cheltenham: Edward Elgar Publishing. doi: 10.4337/9781783471270.00008

Mathai, M. V., Isenhour, C., Stevis, D., Vergragt, P., Bengtsson, M., Lorek, S., et al. (2020). The political economy of (un) sustainable production and consumption: a multidisciplinary synthesis for research and action. Resourc. Conserv. Recycl. 167:105265. doi: 10.1016/j.resconrec.2020. 105265

Mont, O. (2019). A Research Agenda for Sustainable Consumption Governance. Cheltenham: Edward Elgar Publishing. doi: 10.4337/97817881 17814

Mont, O., Heiskanen, E., Power, K., and Kuusi, H. (2013). Improving Nordic Policymaking by Dispelling Myths on Sustainable Consumption. Copenhagen: Nordic Council of Ministers.

Newell, P., Daley, F., and Twena, M. (2021). "Changing our ways? Behaviour change and the climate crisis," in The Cambridge Sustainability Commission on Scaling Behaviour Change (Cambridge: University Press).

Oswald, Y., Steinberger, J., Ivanova, D., and Millward-Hopkins, J. (2021). Global redistribution of income and household energy footprints: a computational thought experiment. Global Sustain. 4:e4. doi: 10.1017/sus.2 021.1

Reisch, L. A., and Thogersen, J. (2015). Handbook of Research on Sustainable Consumption. Cheltenham: Edward Elgar Publishing. doi: 10.4337/978178347 1270

Sahakian, M., Fuchs, D., Lorek, S., and Di Giulio, A. (2021). Advancing the concept of consumption corridors and exploring its implications. Sustain. Sci. Pract. Policy 17, 305-315. doi: 10.1080/15487733.2021.191 9437

Salazar, H. A., Oerlemans, L., and van Stroe-Biezen, S. (2013). Social influence on sustainable consumption: evidence from a behavioural experiment. Int. J. Consum. Stud. 37, 172-180. doi: 10.1111/j.1470-6431.2012.01 110.x

Spangenberg, J. H. (2014). Institutional change for strong sustainable consumption: sustainable consumption and the degrowth economy. Sustain. Sci. Pract. Policy 10, 62-77. doi: 10.1080/15487733.2014.1190 8125

Steg, L. (2015). "Environmental psychology and sustainable consumption," in Handbook of Research on Sustainable Consumption. Cheltenham: Edward Elgar Publishing. doi: 10.4337/9781783471270.0 0012

Steinberger, J. K., Lamb, W. F., and Sakai, M. (2020). Your money or your life? The carbon-development paradox. Environ. Res. Lett. 15:044016. doi: 10.1088/1748-9326/ab 7461

Suski, P., Speck, M., and Liedtke, C. (2021). Promoting sustainable consumption with LCA-a social practice based perspective. J. Clean. Prod. 283:125234. doi: 10.1016/j.jclepro.2020.12 5234

Toulouse, E., Sahakian, M., Lorek, S., Bohnenberger, K., Bierwirth, A., and Leuser, L. (2019). "Energy Sufficiency: How can Research Better Help and Inform Policy-Making?," in ECEEE Summer Study Proceedings.

UN (2015). "Transforming our world: the 2030 Agenda for Sustainable Development," in Resolution 70/1 Adopted by the General Assembly on 25 September 2015. Document a/Res/70/1 (ed.). New York, United Nations. 17th session, Agenda items 15 and 116.: United Nations General Assembly.

UNEP (2020). Emissions Gap Report 2020. Nairobi: United Nations Environment Programme.

United Nations (1992). Agenda 21; Results of the World Conference on Environment and Development. New York: United Nations.

Welch, D., and Warde, A. (2015). "Theories of practice and sustainable consumption," in Handbook of Research on Sustainable Consumption. Cheltenham: Edward Elgar Publishing. doi: 10.4337/9781783471270.0 0013

Wilkinson, R., and Pickett, K. (2010). The Spirit Level: Why Equality is Better for Everyone. New York, NY: Penguin UK.

Conflict of Interest: The author declares that the research was conducted in the absence of any commercial or financial relationships that could be construed as a potential conflict of interest. 
Publisher's Note: All claims expressed in this article are solely those of the authors and do not necessarily represent those of their affiliated organizations, or those of the publisher, the editors and the reviewers. Any product that may be evaluated in this article, or claim that may be made by its manufacturer, is not guaranteed or endorsed by the publisher.
Copyright $\odot 2021$ Lorek. This is an open-access article distributed under the terms of the Creative Commons Attribution License (CC BY). The use, distribution or reproduction in other forums is permitted, provided the original author(s) and the copyright owner(s) are credited and that the original publication in this journal is cited, in accordance with accepted academic practice. No use, distribution or reproduction is permitted which does not comply with these terms. 